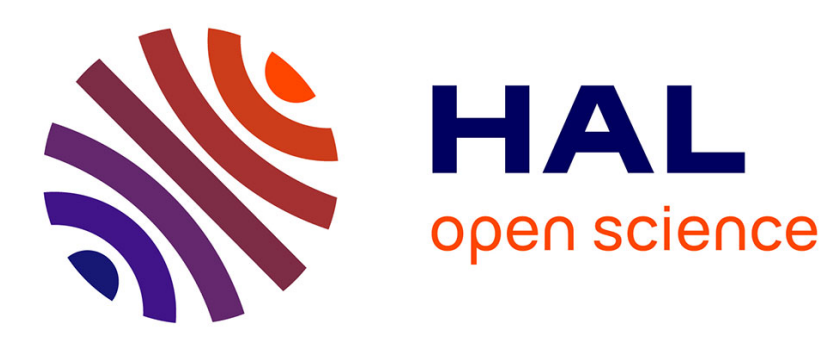

\title{
On nanoparticle formation by laser ablation in liquids
} Tatiana Itina

\section{To cite this version:}

Tatiana Itina. On nanoparticle formation by laser ablation in liquids. Journal of Physical Chemistry C, 2011, 115 (12), pp.5044-5048. 10.1021/jp1090944 . ujm-00629037

\section{HAL Id: ujm-00629037 https://hal-ujm.archives-ouvertes.fr/ujm-00629037}

Submitted on 23 Sep 2021

HAL is a multi-disciplinary open access archive for the deposit and dissemination of scientific research documents, whether they are published or not. The documents may come from teaching and research institutions in France or abroad, or from public or private research centers.
L'archive ouverte pluridisciplinaire HAL, est destinée au dépôt et à la diffusion de documents scientifiques de niveau recherche, publiés ou non, émanant des établissements d'enseignement et de recherche français ou étrangers, des laboratoires publics ou privés. 


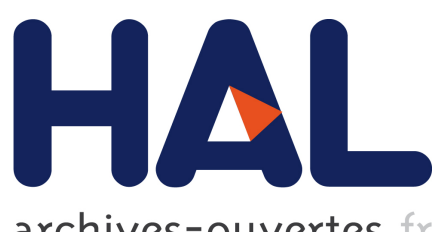

archives-ouvertes

\section{On nanoparticle formation by laser ablation in liquids Tatiana Itina}

\section{To cite this version:}

Tatiana Itina. On nanoparticle formation by laser ablation in liquids. Journal of Physical Chemistry C, American Chemical Society, 2011, 115 (12), pp.5044-5048. 10.1021/jp1090944 . ujm-00629037

\section{HAL Id: ujm-00629037 https://hal-ujm.archives-ouvertes.fr/ujm-00629037}

Submitted on 23 Sep 2021

HAL is a multi-disciplinary open access archive for the deposit and dissemination of scientific research documents, whether they are published or not. The documents may come from teaching and research institutions in France or abroad, or from public or private research centers.
L'archive ouverte pluridisciplinaire HAL, est destinée au dépôt et à la diffusion de documents scientifiques de niveau recherche, publiés ou non, émanant des établissements d'enseignement et de recherche français ou étrangers, des laboratoires publics ou privés. 


\title{
On Nanoparticle Formation by Laser Ablation in Liquids
}

\author{
Tatiana E. Itina*
}

Laboratoire Hubert Curien, CNRS UMR 5516/Lyon University, Saint Etienne, 42000, France

ABSTRACT: Nanoparticle formation by laser ablation in liquids is studied numerically. We investigate such processes as cluster ejection, cluster nucleation, and aggregation. First, laser plume formation, its expansion, and confinement by the liquid are considered. These processes are connected with the formation of two shock waves: one moving inside the solid and the second one propagating in the liquid. If short and ultrashort laser pulses are used, the created plasma plume does not absorb laser radiation. In this case, a larger energy fraction is transferred into the solid during much shorter time, so that the ablation process is explosive. As a result, cluster precursors are ejected directly from the target, and the created plasma is confined to a smaller volume. Shorter laser pulses thus provide more favorable conditions for nanoparticle formation. In addition to the following short plasma expansion stage, a much longer aggregation process occurring in the liquid phase is found to affect the final size distribution.

\section{INTRODUCTION}

During the past decade, the pulsed laser ablation process has been shown to be a promising technique for chemically pure synthesis of nanoparticles (NPs) in liquid solutions. ${ }^{1-4}$ Among the advantages of this method, we can mention the simplicity of the experimental setup, the possibility of synthesis of various materials ranging from metallic ${ }^{5}$ and semiconductor $\mathrm{NPs}^{6}$ to more complex materials ${ }^{7,8}$ and rather complicated structures, such as core-shell NPs. ${ }^{9}$ In addition, laser pulses can be also used to fragment, reshape, and conjugate NPs. ${ }^{10-12}$ Under carefully chosen experimental conditions, the stability of the obtained colloidal solutions can be very high, so that the NPs can be used for many applications in such fields as medicine, sensing, electronics, optics, and biophotonics. Colloidal gold NPs, for instance, are used for tumor-targeted drag delivery and cancer therapy. ${ }^{13,14}$ Plasmonic properties and high resonant absorption of these NPs are also very attractive for photovoltaic cell development and other exciting applications. Both experimental and theoretical studies were carried out trying to optimize experimental parameters and to control the properties of the developed NPs. The polydispersity of the size distribution of these colloidal particles was revealed to be higher than that obtained by wet chemical precipitation..$^{15}$ Many efforts were focused on the reduction of the dispersity. As a result, very narrow size distributions were recently obtained in several experiments. ${ }^{16}$ It was also shown that many factors affect the final size distribution. The presence of surfactant molecules was shown to be crucial for the formation of very narrow NP size distribution. Furthermore, such laser parameters as laser fluence, pulse duration, beam focusing, and repetition rate should be carefully chosen to achieve small size dispersion. In addition, material properties define absorption and the quantity of the ablated material, thus affecting the plasma plume parameters. The formation of laser plasma and its dynamics are also affected by the conditions of strong confinement. In fact, liquid properties such as temperature, mechanical impedance, and viscosity play a role in both shock wave and cavitations bubble formation. In particular, it was demonstrated that smaller laser fluence is a benefit to the synthesis of the smaller particles. ${ }^{17}$ The reduction in the beam size also seems to result in the size decay..$^{18}$ There are several pieces of evidence that shorter pulses can also efficiently reduce the size of the synthesized NPs. ${ }^{19,20}$

To better understand the role of the experimental parameters, NP formation processes should be better understood. Previously, several studies were focused on laser interaction under confinement ${ }^{21}$ and on laser-induced breakdown and cavitation bubble formation in liquids. ${ }^{22}$ In addition, several theoretical models of NP formation were proposed. The analysis of the available experimental findings based on previous models has revealed several mechanisms of NP formation by laser ablation. First, NPs were shown to be ejected directly from the target when short and ultrashort laser pulses were used. Then, nucleation and condensation processes were revealed in the expanding plasma plume. Finally, NP growth in the liquid phase was investigated. Because these processes contribute differently to the formation of NPs under given experimental conditions, it is important to elucidate the mechanisms as a function of such laser parameters as pulse duration and peak intensity.

Herein, we propose a numerical study of the major processes involved in laser ablation into liquids that affect NP formation. The study is aimed at the analysis of the experimental parameters favorable for the formation of small NPs and at the explanation of the experimental results available in the literature As a first case study, we consider gold ablation in water. The roles of such parameters as laser pulse duration and liquid temperature are discussed.

\section{CALCULATION DETAILS AND RESULTS}

We focus our attention on short and ultrashort laser pulses. In this case, the ablation process can be divided into three sages as follows: (i) Early stage-laser energy absorption, material ejection, plume formation; 


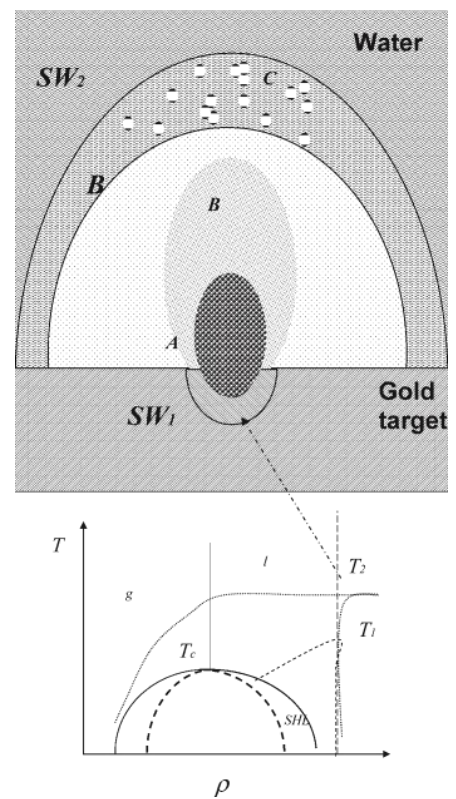

Figure 1. Upper sketch: the formation of two shock waves ( $\mathrm{SW}_{1}$ and $\mathrm{SW}_{2}$ ), laser plume, cavitation bubble ("B"), and the locations of NP formation at early (A), intermediate (B), and late (C) stages. Phase diagram and trajectories demonstrate the typical processes of the target material expansion in a vacuum (1) and in the presence of liquid (2). Here "superheated liquid" (SHL), liquid ("1"), and gas (" $\mathrm{g}$ ") are shown; $\mathrm{T}_{\mathrm{c}}$ is the critical point.

(ii) Intermediate stage-plume expansion in the presence of a confining liquid environment;

(iii) Late stage-plume mixing with the liquid, NP coalescence/aggregation processes.

The laser spot is typically large enough, so that onedimensional approximation is used for the early stage. Here, for simplicity, such processes as collisional fragmentation and chemical reactions with surfactant molecules in the liquid are neglected.

A. Early Stage. We consider an interaction of a laser pulse with a gold target in the presence of water. During laser pulse, the target material absorbs laser energy. Then, energy relaxation leads to the formation of heat waves followed by the generation of two shock waves: one propagating inside the target $\left(\mathrm{SW}_{1}\right.$ in Figure 1$)$ and another one moving outside through the liquid material $\left(\mathrm{SW}_{2}\right)$. When nanosecond or longer laser pulses are used, according to the model of Fabbro et al., ${ }^{23}$ a part of the laser energy is considered to be absorbed by the generated laser plasma and transformed in the internal energy $\mathrm{E}_{\mathrm{i}}$. In this case, the energy conservation law requires that the laser intensity

$$
I(t)=P(t) \frac{d L(t)}{d t}+\frac{d\left[E_{i}(t) L(t)\right]}{d t}
$$

where $P$ is pressure experienced by the plasma plume; $L$ is the length of the plasma plume; and $E_{i}$ is the internal energy of the created plasma. The latter can be presented as a sum of the thermal energy $E_{t h}=R E_{i}$ and the energy fraction used for plasma ionization, $(1-R) E_{i}$. Here, $R$ determines the energy fraction transferred to the thermal energy of the plume. Using the ideal gas assumption, the integration can be performed analytically for top-hat laser pulse. At the end of the first stage ( $\tau$ is laser pulse for nanosecond laser), one obtains

$$
\begin{aligned}
& P_{0}=P(\tau)=\sqrt{\frac{\alpha}{2 \alpha+3} Z I_{0}} \\
& L_{0}=L(\tau)=\frac{4 \tau}{3} \sqrt{\frac{\alpha}{2 \alpha+4} \frac{I_{0}}{Z}}
\end{aligned}
$$

In the case of short (picosecond) and ultrashort (femtosecond) laser ablation, plume does not absorb laser energy, so that $E_{t h}=R E_{i}$ is smaller. In addition, a fraction of the ablated material can ${ }^{24}{ }^{26}$ be ejected in the form of particles and clusters. This result was previously obtained in a number of simulations and experiments performed for ultrashort laser ablation in vacuum refs. In the presence of a confining liquid environment, stronger shock waves are typically initiated in the target to create a rarefaction wave inducing the ablation event. In other words, the ablation process starts at higher laser fluences if laser ablation takes place in liquid. As a result, the target material is heated to higher temperatures $\left(T_{2}>T_{1}>T_{c}\right.$, where $T_{c}=7400(1100 \mathrm{~K}$ is the critical temperature of gold corresponding to the critical pressure of $530\left(20 \mathrm{MPa}^{27}\right.$ ), so that more trajectories ${ }^{25}$ pass above the critical point, as one can see in the (T,F) phase diagram (Figure 1). The larger material fraction is, therefore, atomized, and the smaller one is ejected in the form of particles, as molecular dynamics simulations indicated. ${ }^{28}$ Equations 2 and 3 thus can be used for ultrashort pulses in liquid, but $\tau$ should stand for the electronphonon/ion relaxation time in this case. These equations clearly show that the initial plume length is smaller, whereas the initial pressure is larger for ultrashort laser pulses than for longer ones.

B. Intermediate Stage. During this stage, laser plume expands almost adiabatically behind the shock wave and the wall of the cavitation bubble (Figure 1). The common equations for the adiabatic expansion yield the following expressions for plasma length and pressure as a function of time 


$$
\begin{aligned}
& P(t)=P_{0}\left[1+\frac{\gamma+1}{\tau}(t-\tau)\right]^{-\gamma / \gamma+1} \\
& L(t)=L_{0}\left[1+\frac{\gamma+1}{\tau}(t-\tau)\right]^{1 / \gamma+1}
\end{aligned}
$$

where $\gamma$ is the adiabatic parameter. One can see that the final length and pressure are determined by the corresponding initial values and the parameter $\gamma$, which can be taken to be $\gamma=1 \mathrm{p} 2 \mathrm{R} / 3$. At this stage, therefore, the plume number density is higher, whereas the plume temperature is smaller in the case of shorter pulses. These facts favor nucleation leading to the formation of small NPs ( $n$-monomer nucleus), whose size is controlled by the free energy as follows

$$
\Delta G(n, c)=-n k T \ln \left(c / c_{0}\right)+4 \pi a^{2} n^{2 / 3} \sigma
$$

where $\mathrm{k}$ is the Boltzmann constant; $\mathrm{T}$ is the temperature in Kelvin; $a$ is the effective radius of plume species (gold atoms here); $\mathrm{c}$ is the concentration; $\mathrm{c}_{0}$ is the equilibrium concentration; and $\sigma$ is the effective surface tension. We note that the surface energy term plays a crucial role in the formation of small clusters. The peak of the nucleation barrier corresponds to the critical cluster size

$$
n_{c}=\left[\frac{8 \pi a^{2} \sigma}{3 k T \ln (S)}\right]^{3}
$$

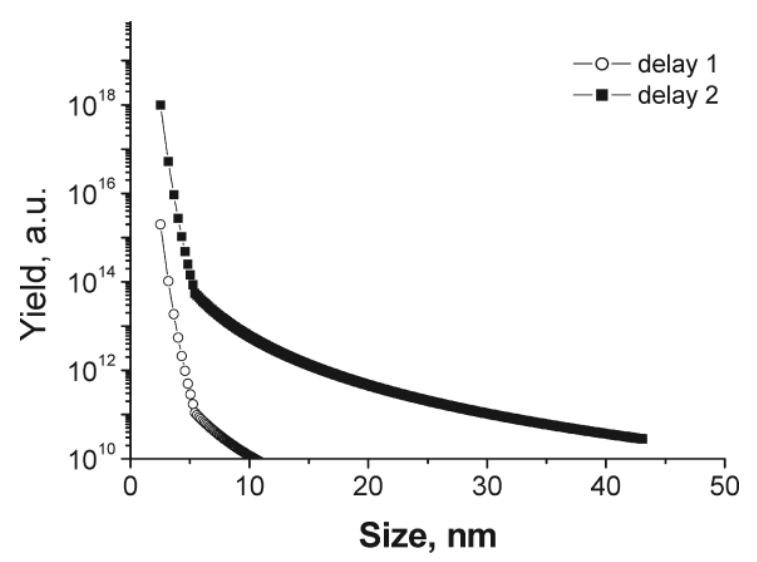

Figure 2. Size distribution of gold NPs before the plume-liquid mixing obtained in MD-DSMC simulations. ${ }^{29}$ Here, laser pulse width is $100 \mathrm{fs}$; laser wavelength is $800 \mathrm{~nm}$; and laser fluence is twice the ablation threshold. The dependencies are shown for a time delay of $150 \mathrm{ps}$ (delay 1 ) and $1 \mu \mathrm{s}$ (delay 2 ) after the beginning of the laser pulse.

where $S$ is the super saturation parameter ( $S>1$ is required). The nuclei formed at this stage can evaporate or grow due to both monomer and cluster addition. Their growth in plasma can take place only until the density of the plasma drops and collisions cease. This process prevails over evaporation only if the temperature of both clusters and plasma is not too high. $^{29}$ If laser intensity is high enough, a so-called "cavitations bubble" is known to form in the liquid, so that the plasma plume expands inside it. Commonly, bubble collapse time is around ${ }^{22} 50-100 \mu \mathrm{s}$. In the case of ultrashort laser pulses and when plume does not absorb laser energy, a collisional quenching effect occurs at the delays of only several microseconds. According to the combined molecular dynamics-direct Monte Carlo (MD-DSMC) simulations, by that time, the size of NPs is rather small, and their typical size distribution can be fitted by a decreasing function $^{24,26,30,29}$ (Figure 2). We consider these clusters as seeds for the following much longer nucleation and growth process that occurs at a later stage.

C. Late Stage. At the later stage, plume species (atoms and clusters) mix with the surrounding liquid, forming a solution. The initial parameters of this solution, such as solute concentration, temperature, particle size, and density determine its following evolution. If the parameters of this solution are such that it is supersaturated, then additional nucleation and growth of NPs take place in the solution. Sequential application of temporally separated laser pulses enhances solution concentration and favors nucleation at this stage. The rate of production of critical clusters at this stage is given by

$$
\rho(t)=4 \pi a n_{c}^{1 / 3} D c^{2} \exp \left[\frac{-\Delta G\left(n_{c}, c\right)}{k T}\right]
$$

$D$ is the diffusion coefficient of gold atoms in the liquid (water here).

If the number of the produced nuclei is high enough for collisions among them, this process is followed by coalescence (liquid nuclei) or aggregation (solid particles), thus increasing considerably particle size. In this study, we consider this process to be prevailing at the late stage. Then, the cluster time-evolution can be described by simplified master equations. ${ }^{31,32}$ The evolution of the singlet population is given by

$$
\frac{d N_{1}}{d t}=\rho(t)-\sum_{j=2}^{\infty} j \frac{d N_{J}}{d t}
$$




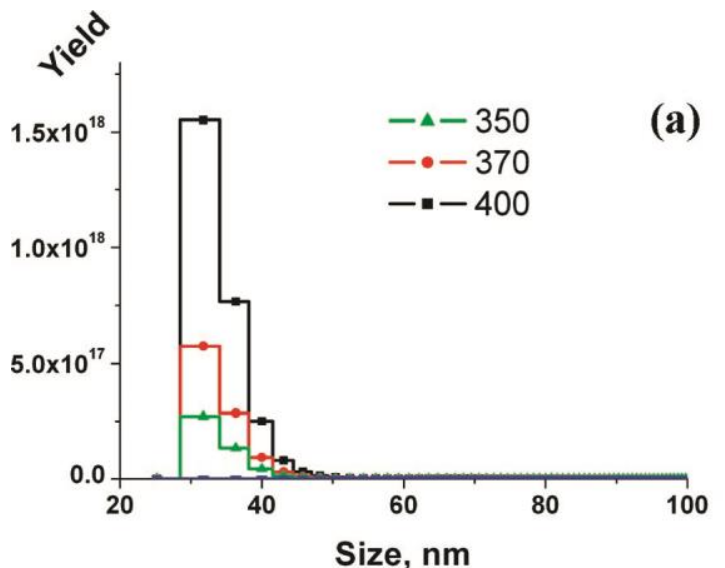

(b)

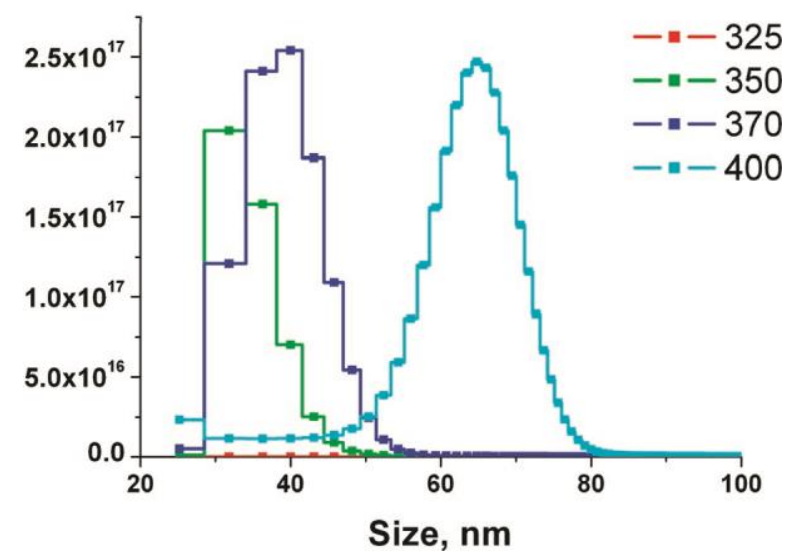

Figure 3. Size distribution of gold NPs obtained as a result of nucleation and aggregation in liquid (water) solutions. Here, different parameters were used as follows: (a) solution concentration is $3.510^{21} \mathrm{~m}^{-3}$, and solution temperature is varied as

shown in the legend; (b) the same for the solution concentration of $3.510^{22} \mathrm{~m}^{-3}$.

$\frac{d N_{2}}{d t}=f K_{1} N_{1}^{2}-K_{2} N_{1} N_{2}$

and for $s=2$

$\frac{d N}{d t}=K_{s-1} N_{1} N_{s-1}-K_{s} N_{1} N_{s} \quad(s \geq 3)$ where $\mathrm{N}_{s}(\mathrm{t})$ is the time-dependent number density of the secondary particles containing s primary particles; $K_{s}=4 \pi\left(R_{1}\right.$ $\left.p R_{s}\right)\left(D_{1} p D_{s}\right)$ is the attachment rate constant; $R_{s}=1.2 r s^{1 / 3} ; r$ is

the

average radius of the primary particle; $D_{s}=D_{1} S$ is the diffusion coefficient of aggregates containing s singlets. The diffusion coefficient of a singlet (critical nucleus here) $D_{1}$ is given by the Stokes-Einstein relation and depends on water viscosity and temperature.

At this stage, the diffusion coefficient and, in particular, its temperature dependency should be properly described. For water, we used the following expressions ${ }^{33}$

$$
D=\frac{k T}{6 \pi \eta \sigma}
$$

where $\eta=A 310^{B /(T-C)}$ is viscosity; $A=2.41410^{-5} \mathrm{~Pa} \mathrm{~s} ; \mathrm{B}=$ 247.8 K; and C $=140 \mathrm{~K}$. Note that these equations reveal a quite

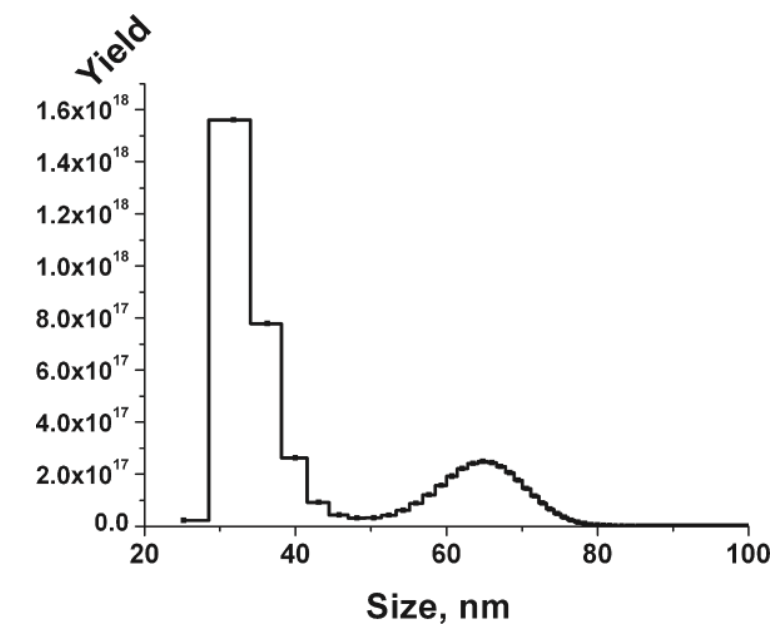

Figure 4. Bimodal size distribution obtained in the calculation with two different solution concentrations, $3.510^{21} \mathrm{~m}^{-3}$ and $3.510^{22} \mathrm{~m}^{-}$ ${ }^{3}$, and temperature of $400 \mathrm{~K}$.

strong temperature dependency of the particle diffusion process in water. Therefore, if laser pulse is long or many laser shots are applied, particles absorb laser radiation, and water temperature increases, the final size distribution of 
NPs and their mean hydrodynamic diameter can be affected. $^{34}$

The calculated size distributions of NPs obtained at two different temperatures are shown in Figures 3(a) and 3(b). One can see that if the solution concentration is small at the beginning of this late stage then the increase in water temperature affects only the total number of particles, whereas the mean hydrodynamic diameter stays almost unchanged. At larger solution concentrations, the mean hydrodynamic diameter rises with water temperature (in the considered temperature range). This result consists with the previous experimental findings. ${ }^{34}$ Higher temperatures are not considered since this case is connected with strong light absorption by NPs and can lead to their explosion and decrease in the mean diameter. These effects are out of the subject of the present study.

It remains finally to explain frequent experimental observations of bimodal size distributions. ${ }^{4}$ On the basis of the obtained calculation results, we can suggest that this kind of distribution is caused by a sudden increase in the solution concentration. This increase can be due to the bubble collapse and plasma erosion of the surface, as noticed in ref 4. In addition, multiple ablation events leading to the accumulation of ablated material in the liquid also favor this effect. The resulting size distribution can be presented as a sum of two or several distributions obtained for different water temperatures (Figure 4).

\section{SUMMARY}

The results of numerical calculations performed keeping only the essential physics have provided a comprehensive analysis of the NP formation process. This analysis has shown that ultrashort laser ablation provides small NPs with a stable size distribution if experimental parameters are carefully chosen. In addition, the calculation results have confirmed the fact that the liquid solution temperature may have a dramatic effect on the mean hydrodynamic diameter if the concentration of the solution overcomes a certain stability limit. Finally, the results agree with previous suggestions that a bimodal size distribution of NPs can be explained by a sudden rise in the solution concentration due to effects such as plasma erosion of the surface upon bubble collapse.

The presented results can be used to better understand many experimental findings obtained during laser ablation in liquids. Further investigations of the role of surfactant molecules, more complicated chemical reactions, multiple laser shots, and other required effects will be an object of our future research.

\section{'AUTHOR INFORMATION}

\section{Corresponding Author}

*E-mail: tatiana.itina@univ-st-etienne.fr. Fax: p33 (0)477

915781. Tel.: p33 (0)477915780.

\section{'ACKNOWLEDGMENT}

Computer support provided by the CINES of France under the project number c2011085015 is gratefully acknowledged. PACS: 82.60.Qr, 65.80.pn, 02.70.Ns, 63.22.Kn.

\section{'REFERENCES}

(1) Yang, G. W. Prog. Mater. Sci. 2007, 52, 648.

(2) Mafune, F.; Kohno, J.; Takeda, Y.; Kondow, T.; Sawabe, $\mathrm{H}$.

J. Phys. Chem. B 2003, 107, 4218.

(3) Simakin, A. V.; Lubnin, E. N.; Shafeev, G. A. Quantum Electron. 2000, 30, 263.

(4) Kabashin, A. V.; Meunier, M. J. Phys.: Conf. Ser. 2007, 59,354

(5) Stratakis, E.; Zorba, V.; Barberoglou, M.; Fotakis, C.; Shafeev,

G. A. Appl. Surf. Sci. 2009, 255, 5346.

(6) Sajti, C. L.; Giorgio, S.; Khodorkovsky, V.; Marine, W. Appl. Phys. A: Mater. Sci. Process. 2007, 89, 315.

(7) Sajti, C. L.; Sattari, R.; Chichkov, B. N.; Barcikowski, S. J. Phys. Chem. C 2010, 114, 2421.

(8) Ledoux, G.; Amans, D.; Dujardin, C.; Masenelli-Varlot, K. Nanotechnology 2009, 20, 445605.

(9) Kazakevich, P. V.; Simakin, A. V.; Voronov, V. V.; Shafeev, G. A.; Starikov, D.; Bensaoula, A. Diffus. Defect Data, Pt. B 2005, 106, 23.

(10) Besner, S.; Kabashin, A. V.; Meunier, M. Appl. Phys. Lett. 2006, 89, 233122.

(11) Zhao, Q.; Hou, L.; Zhao, Ch.; Gu, S.; Huang, R.; Ren, Sh. Laser Phys. Lett. 2004, 1, 115.

(12) Petersen, S.; Jakobi, J.; Barcikowski, S. Appl. Surf. Sci. 2009, 255, 5435.

(13) Paciotti, G. F.; Myer, L.; Weinreich, D.; Goia, D.; Pavel, N.; McLaughlin, R. E.; Tamarkin, L. Drug Delivery 2004, 11, 169.

(14) Cai, W.; Chen, X. Small 2007, 3, 1840.

(15) Muto, H.; Miyajima, K.; Mafune, F. J. Phys. Chem. C 2008, 112, 5810 .

(16) Sylvestre, J.-P.; Kabashin, A. V.; Sacher, E.; Meunier, M. Appl. Phys. A: Mater. Sci. Process. 2005, 80, 753.

(17) Mafune, F.; Kohno, J.; Takeda, Y.; Kondow, T.; Sawabe, $\mathrm{H}$.

J. Phys. Chem. B 2001, 105, 5114.

(18) Pyatenko, A.; Shimokawa, K.; Yamaguchi, M.; Nishimura, O.; Suzuki, M. Appl. Phys. A: Mater. Sci. Process. 2004, 79, 803 .

(19) Mafune, F.; Kohno, J.; Takeda, Y.; Kondow, T.; Sawabe, H. J. Phys. Chem. B 2000, 104, 9111.

(20) Tsuji, T.; Kakita, T.; Tsuji, M. Appl. Surf. Sci. 2003, 206, 314.

(21) Fabbro, R.; Fourntier, J.; Ballard, P.; Devaux, D.; Virmont, J. J. Appl. Phys. 1990, 68, 775.

(22) Vogel, A.; Venugopalan, V. Chem. Rev. 2003, 103, 577.

(23) Fabbro, R.; Peyre, P.; Berthe, L.; Scherpereel, X. J. Laser Appl. 1998, 10, 265.

(24) Leveugle, E.; Zhigilei, L. V. Appl. Phys. A 2004, 79, 753.

(25) Povarnitsyn, M. E.; Itina, T. E.; Sentis, M.; Khishenko, K. V.; Levashov, P. R. Phys. Rev. B 2007, 75, 235414. 
(26) Heiroth, S.; Koch, J.; Lippert, T.; Wokaun, A.; Gunther, D.; Garrelie, F.; Guillermin, M. J. Appl. Phys. 2010, 107 (1), No. 014908.

(27) Boboridis, K.; Pottlacher, G.; J€ager, H. Int. J. Thermophys. 1999, 20, 1289.

(28) Perez, D.; Beland, L. K.; Deryng, D.; Lewis, L. J.; Meunier, M. Phys. Rev. B 2008, 77, No. 014108.

(29) Gouriet, K. PhD thesis, Mediterranean Universtity, Marseille, France, 2008.

(30) Hermann, J.; No€el, S.; Itina, T. E.; Axente, E.; Povarnitsyn, M. E. Laser Phys. 2008, 18, 374.

(31) Smoluchowski, R. V. Z. Phys. Chem. 1917, 29, 129.

(32) Park, J.; Privman, V.; Matijevic, E. J. Phys. Chem. B 2001, 105, 11603.

(33) Seeton, Ch. J. Tribol. Lett. 2006, 22, 67.

(34) Mendes-Manjon, A.; Chichkov, B. N.; Barcikowski, S. J.

Phys.

Chem. C 2010, 114, 2499. 